\title{
To Adapt MOOCS, or Not? That is No Longer the Question
}

\author{
Sarah M. North ${ }^{1, *}$, Ronny Richardson ${ }^{2}$, Max M. North ${ }^{3}$ \\ ${ }^{1}$ Computer Science Department, Kennesaw State University \\ ${ }^{2}$ Business Administration Department, Southern Polytechnic State University \\ ${ }^{3}$ Management Information Systems, Southern Polytechnic State University \\ *Corresponding Author: snorth@kennesaw.edu
}

Copyright (C) 2014 Horizon Research Publishing All rights reserved.

\begin{abstract}
Massive Open Online Courses (MOOCs) are the next logical phase of distance learning rapidly appearing on the horizon. A recent worldwide survey shows that the adoption of MOOCs is on the rise. This study focuses on identifying and emphasizing the unique advantages of MOOCs and provides possible insights to better understanding of MOOCs as an evolutionary product of classical distance learning. Two simple preliminary experiments were designed and conducted to investigate approaches for strengthening trust in MOOCs adaptation. While this is a work-in-progress, the authors provide several preliminary recommendations to assist in the decision making process for gradual adaptation of MOOCs in conjunction with complementary in-house components.
\end{abstract}

Keywords MOOCs, Distance Learning, Education

\section{Introduction}

Online education is certainly not a new approach for learning and teaching in globally disparate environments; it is an approach that has been steadily evolving for years. Massive Open Online Courses (MOOCs) are a logical product of this evolution. Online course offerings are one of the most effective and efficient delivery methods for contents and skills globally. There are many common senses advantages to the online course approach, including the wide flavor of degree programs and classes offered, flexible study times, and the ability for students to balance between a career and education. Although the online movement is growing dramatically, leading to more creative philosophies such as MOOCs, it cannot be considered a true revolution. Yet it cannot be ignored for the simple reason that it promotes sharing information worldwide and has created many opportunities for teaching and learning in a variety of disciplines $[1,19,20,21]$. According to a recent worldwide survey, the adoption of MOOCs is on the rise [2,3]. Here are a few important responses to the trend that should cause universities to seriously pay attention to MOOCs: "90 percent of schools offer or plan to offer online courses in the next 3 years - 74 percent offer today," "2013 - Only 13 percent of schools offer MOOC; but 43 percent plan to offer MOOCs by 2016," "Only 44 percent of schools are planning to offer MOOC credits!" "83 percent of schools would consider joining an online education group such as edX, Coursera, or Udacity," and "67 percent of schools believe that MOOCs will never replace traditional, residential classes; 5 percent said yes within 5 years!" Quoted directly from the survey results [3]. Thus, "To adapt MOOC or not?" is no longer a question. It is a logical outcome of the ongoing evolution of distance learning.

\section{MOOCS Differentiation Factors}

Among the pioneers of the MOOC is the MIT OpenCourseWare-provided, individual, self-paced learning environment and the recently incorporated, open-source learning management system Moodle. At a more limited level, many universities and colleges are offering either hybrid- or fully-online courses in many departments, such as Business Administration, Accounting, Mathematics, English, Physics, and Chemistry, just to name a few. As empirical research shows, building an effective traditional online course is no longer that difficult. For instance, for developing a course for Management Information Systems, a designer at the minimum needs to identify the topics to be covered, lectures to be developed based on each topic, discussions, assignments, quizzes, periodical tests (such as first, midterm, third, and final tests), and of course, course syllabi and instructions with due dates to guide students through the course. Fundamentally, the same or similar techniques work for developing MOOCs [7]. While there exist a number of advantages and disadvantages for either of these methods; only the most important of MOOCs differences are discussed and will be addressed in this paper:

- Motivation. MOOCs currently and generally are developed by elite universities using prominent 
professors [5]. The consequences of this approach are two-fold: (i) it serves as a great global marketing technique for universities and (ii) provides opportunities for faculty involved to sell course materials, textbooks and other related items. On the other hand, student motivation to take these types of courses includes curiosity or getting certificates from the elite universities, boosting their ego and possibly their resumes.

- Enormous enrollment. MOOCs have the potential to engage a large number of students - thousands - to take a single course. For instance, Stanford's course on artificial intelligence, taught by two "celebrity professors," attracted 150,000 students. The class size may be intimidating to instructors, and the common tasks of regular interaction and evaluation are almost impossible; however, a recent report demonstrates the massiveness of MOOCs is a net boon, because it can energize students and faculty experiences $[19,20]$.

- Retention. One of the major challenges of MOOCs is drop rate [9]. Since students do not invest any financial resources, it is easy for them to drop a course at any time without any of the consequences that they would have faced with traditional courses. Courses commonly only have a $10 \%-20 \%$ completion rate $[7,22]-$ a few anecdotal reports denote as low as $2 \%$ completion rate.

- Diversity and disparity. Students who are taking MOOC courses inherently represent wider and larger diversity compared with traditional structured curriculum courses. MOOCs experience a wider variety of elements such as background education, specific knowledge and skill, just to list a few. While like the traditional online courses, students geographically present disparity, naturally the magnitude is much larger with the MOOCs offerings [20].

- Interaction and feedback. Almost no one in a MOOC receives individual interaction or attention from an expert. Lack of consistent review and grading system further weakens the already non-existent interaction, which ultimately provides unacceptable feedback compared with traditional learning [8]. Generally, the evaluation of students' work utilizes guided peer assessment, which, in turn, opens up new safety and privacy issues [19].

- Plagiarism and cheating. These are widely discussed challenges in online education $[10,11,12,13,14,15$, 16, 17]. Plagiarism-detection software such as common software and services provided by turnitin.com are becoming very usual in detecting plagiarism. However, while cheating online is not that easy to detect, there are common sense solution to address this issue $[6,11]$. Recently, both edX and Udacity have partnered with Pearson VUE, a provider of testing centers, to validate students taking proctored tests $[11,18]$.

- Success rate. While thousands enroll for the MOOC courses, the completion rate is extremely low; this makes it challenging to determine whether MOOCs are successful [5,7]. Studies report completion rates of between $10 \%$ and $20 \%$ (80-90\% non-completion rate), and an even smaller rate of students actually receive certificates. It must be noted that "completion" is different from "learning," and yet there are no reliable data to support the MOOCs learning outcomes.

The above list is not presented as exhaustive; it is merely what seems to be most obvious and important at this time. As obvious as it is, it must be stated that MOOCs are different from traditional online delivery methods. As it has been discussed by many experts and researchers in this field, many challenges need to be overcome for MOOCs to become competitive with the classical model of online education $[4,9]$. The main objective of this study was to investigate MOOCs differences and attempt to either resolve them or find alternative approaches toward at least making the MOOCs more effective, thus providing information supporting the wider adoption of MOOCs at universities. This is an ambitious endeavor to embrace. Therefore, after a careful review of extant literature and consideration of limited resources, the authors decided to approach this challenge one item at a time, during multi-year phases. Obviously, conducting several pilot studies with smaller pools of subjects (students and faculty in this case), seems to be a logical and practical approach. Cheating and success rate differences seem to have priority to be investigated before any other items being considered. For that reason, two experiments were designed and conducted simultaneously. A brief summary of both experiments are described below. A complete report of the first experiment can be found by following the citation in the reference section [6]. Experiment-II is a simple survey research, and results are preliminary at this time; however, a complete, solid research program will be designed, conducted, and reported in the next several phases.

\section{Pliminary Experiements}

\subsection{Experiment-I: Plagiarism and Cheating}

The objective of the experiment-I was two-fold; first, to investigate plagiarism and cheating related to the online courses; second, to offer validated solutions. For clarity, the following definitions are used in this study: (i) Plagiarism occurs where a student represents the work or ideas of another person as his or her own; and (ii) Cheating occurs where a student or group of students uses or attempts to use unauthorized aids, assistance, materials or methods. Plagiarism is easier to be detected by specialized software, while cheating is much harder to be identified or prevented without human intervention. In this experiment, the focus 
was on strengthening the trust in online courses by using a common-sense approach: proctoring major tests. To validate the approach, students in several business and accounting courses were given several proctored and non-proctored tests. Results demonstrated that grades on the proctored tests were lower than the same non-proctored tests in other sections of the courses (statistically significant difference) - see Figure 1. Interestingly, the difference between proctored and non-proctored tests was much lower at the graduate level than at the undergraduate level, but still statistically significant different [6]. For a complete report, please access the article "Strengthening the Confidence in Online Courses: A Common Sense Approach" listed in the reference section of this paper [6].

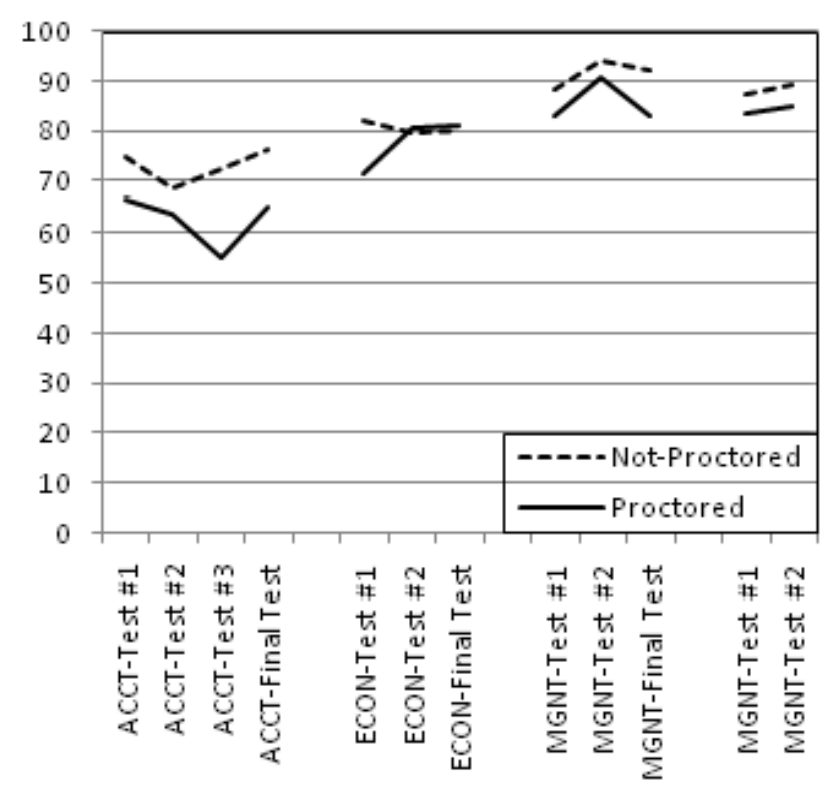

Figure 1. Results showing comparison of Non-Proctored and Proctored tests.

\subsection{Preliminary Experiment-II: Success Rate}

The main objective of this experiment was to conduct a simple survey of a small sample who took MOOCs and to determine the relationship between level of difficulty and success rate (perceived learning outcomes) associated with courses. Inspiration for this quick and minute experiment came from a similar, but extensive, study that has been recently conducted by researchers at the University of Helsinki [2]. Simply, this was a preliminary pilot study involving 72 participants who took courses offered by the MOOC's institutions. Participants were asked to report numeric feedback on the general course difficulty (scale of 1 to 10 , with 1 being easy and 10 being difficult). They also were requested to provide numeric feedback on their perceived learning outcomes (simply, the level of learning they perceived they achieved) using the same scale of 1 to 10 ( 1 denoting that perception of learning was very low and 10 denoting that the perception of learning was very high). The preliminary results are shown in Figure 2 and visually demonstrate no correlation between level of difficulty and perceived learning outcome of MOOC experiences. Since the subject pool was extremely limited and the subject matter was not restricted, the results of this experiment cannot be statistically validated. This specific methodology was used and is similar to the rapid prototyping approach in building software and interfaces; there will be additional iterations of this methodology for future experiments. As a bonus value, perhaps, authors can observe how the data and results evolve during the iterative process, but that is not within the scope of this current paper. To reemphasize, this attempt was just a simple pilot study, and authors have already designed and are planning to conduct more solid experiments soon. Even knowing about the possible flaws of the approach, the results are interesting to observe, but no serious conclusions should be drawn from the data at this stage.

\section{Level of Difficulty/Learning Outcome}

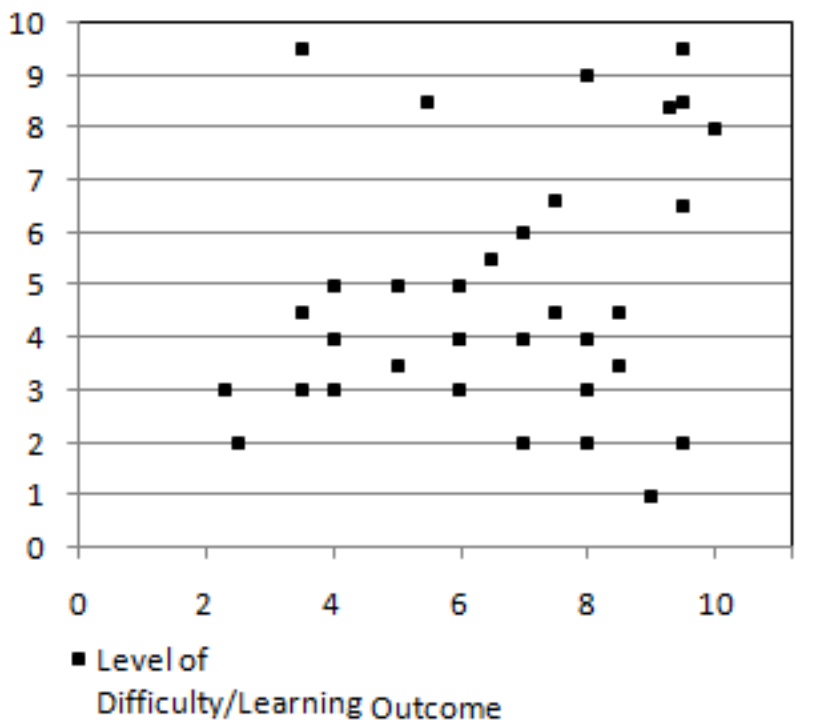

Figure 2. Showing relationship between participants' responses on level of difficulty and learning outcomes.

\section{Discussion and Recommendations}

This study is a work in progress, and it reports only a small phase of a multi-year research endeavor. It is anticipated that the preliminary results provide an informal, initial data in assisting faculty and administrators in the decision making process for MOOC adoption. Based on the brief literature review, the preliminary data collected from the two experiments described briefly in this paper, and informal feedback of the limited participants, MOOCs seem to be a good, if incomplete, choice for course supplementation at this time [19]. If the MOOC is going to be used in conjunction with traditional online courses, additional complementary components need to be developed and provided. In order to be used as an effective method of delivery comparable with traditional approaches. factors 
such as interaction and feedback, success rate, and plagiarism and cheating need to be addressed within the in-house components of the online course. While the impact of the first five MOOC factors (motivation, enormous enrollment, retention, diversity and disparity, interaction and feedback) listed in this paper cannot be ignored, there is not much that the individual institution can do about any of these factors. However, the last two MOOC factors (plagiarism and cheating, and success rate) can be easily resolved by using the common-sense practices that have been working for traditional online courses in the past. Other simple alternative strategies may be to have students to take a challenge test to validate their learning outcome. However, this alternative is not logically aligned with the main MOOC objective and goals. While MOOCs are in their infancy and need resources and time to evolve into a fully effective and efficient educational platform, their potential and movement cannot be ignored. The authors recommend a limited adoption of this technology as a logical and useful decision at this stage, along with providing complementary in-house components to address the major important MOOC shortcomings.

\section{REFERENCES}

[1] Martin, F.G., Will massive open online courses change how we teach? Communications of the ACM, August 2012, 55(8), 26-28.

[2] Vihavainen, A., Luukkainen, M., Kurhila, J., Multi-faceted Support for MOOC in Programming, ACM Joint Conference SIGITE/RIIT, Canada, Alberta, 2012.

[3] Afshar, V., Adoption of Massive Open Online Courses [Worldwide Survey], Retrieved on June 20, 2013: http://www.huffingtonpost.com/vala-afshar/infographic-ado ption-of-m_b_3303789.html

[4] Cooper, S., Sahami, M., Education Reflections on Stanford's MOOCs, New possibilities in online education create new challenges. Communications of the ACM, February 2013, 56(2), 28-30.

[5] Sahami, M., Martin, F. G., Guzdial, M., Parlante, N., The Revolution Will Be Televised: Perspectives on Massive Open Online Education, ACM-SIGCSE'13, Denver, Colorado, USA, March 2013, 457-458.

[6] Richardson, R., North, M.M., Strengthening the Confidence in Online Courses: A Common Sense Approach, The Journal of Computing Science in Colleges, The Journal of Computing Science in Colleges CCSC (Consortium for Computing Sciences in Colleges), May 2013, 28(5), 266-272.

[7] Malan, D.J., Implementing A Massive Open Online Course (MOOC), Tutorial Presentation, Journal of Computing Sciences in Colleges, June 2013, 28 (6), 136-137.
[8] Carlson, R., Assessing Your Students: Testing in the Online Course, Syllabus, 12(7), 16-18, 2000.

[9] To MOOC or Not to MOOC? What's In It For Me? Retrieved on June 20, 2013: http://edwired.org/2013/05/07/to-mooc-or -not-to-mooc-whats-in-it-for-me/

[10] Young, J. Dozens of plagiarism incidents are reported in Coursera's free online courses. The Chronicle of Higher Education (May 26, 2013). http://chronicle.com/article/Doze ns-of-Plagiarism-Incidents/133697/

[11] Parry, M. EdX offers proctored exams for open online course. The Chronicle of Higher Education, September 6, 2012.

[12] Prince, D.J., Fulton, R.A., Comparisons of proctored versus non-proctored testing strategies in graduate distance education curriculum, Journal of College Teaching \& Learning, November 2009, 6(7)), 51-62.

[13] Rowe, N., Cheating in online student assessment: Beyond plagiarism, Online Journal of Distance Learning Administrat ion, Retrieved on June 1, 2012 on http://www.westga.edu

[14] Bosch, T., Why Would Someone Cheat on a Free Online Class That Doesn't Count Toward Anything? Posted Monday, Aug. 20, 2012. Retrieved on June 11, 2013: http://www.slate.com/blogs/future tense/2012/08/20/courser a plagiarism why would students cheat in a_free_online_class_that_doesn_t_over_academic_credit_ht $\mathrm{ml}$

[15] Rogers, C. F., Faculty perceptions about e-cheating during online testing, Consortium for Computing Sciences in Colleges, December 2006, 22(2), 206-212.

[16] Greenberg, R., Online Testing, Techniques: Making Education \& Career Connections, 73(3), 26-28, 1998.

[17] Baker, R., Papp, R., Academic Integrity Violation in the Digital Realm, Proceedings from the Southern Association for Information Systems 2003-Annual Conference, 193-202, 2003.

[18] Udacity blog. Udacity in partnership with Pearson VUE announces testing centers. Retrieved on June 20, 2013: http://blog.udacity.com/2012/06/udacity-inpartnership-withpearson-vue.html

[19] Head, K., Massive Open Online Adventure, The Digital Campus-Chronicle of Higher Education, Retrieved on June 18, 2013: http://chronicle.com/article/Massive-Open-OnlineAdventure/138803/

[20] Roth, M., My modern experience teaching at MOOC, Retrieved on June 20, 2013: http://chronicle.com/article/MyModern-MOOC-Experience/138781/

[21] The Digital Campus 2013, Major Players in the MOOC Universe, The Chronicle of Higher Education, June 22, 2013. $\mathrm{http}: / /$ chronicle.com/article/The-Major-Players-in-the-MOO C/138817/ MOOC Universe

[22] MOOC Completion Rates: The Data. Retrieved on June20, 2013: http://www.katyjordan.com/MOOCproject.html 